\title{
Glasgow Coma Scale: \\ Sykepleieres vurdering av bevissthetsnivå etter akutt forgiftning varierer
}

Glasgow Coma Scale kan være et nyttig verktøy for å vurdere intoksikasjonspasienters bevissthetsnivå, men det forutsetter at personalet lærer seg å skåre pasientene likt.

\section{Forfatter}

\section{Aina Evensen Helme}

Sykepleier

Intensivavdelingen, Ullevål sykehus, Oslo universitetssykehus

\section{Nøkkelord}

\begin{tabular}{l|l|l|l} 
Intoksikasjon Forgiftning Glasgow coma scale Overdose &
\end{tabular}

Sykepleien 2018 106(70889)(e-70889)

DOI: https://doi.org/10.4220/Sykepleiens.2018.70889

HOVEDBUDSKAP

I undersøkelsen denne artikkelen bygger på, brukte to sykepleiere Glasgow Coma Scale (GCS) til å skåre den samme pasienten på tilnærmet samme tidspunkt uten å se hverandres skåringer. Resultatet var et lavt samsvar mellom de parallelle skåringene.

GCS kan oppleves som et komplisert klinisk verktøy. Trening av personalet i bruk av skåringsverktøyet er viktig. Det anbefales bruk av en standardisert manual med praktiske forklaringer av skåringsprosessen.

Implikasjonen for videre praksis er at GCS kan anses som et reliabelt verktøy til pasienter med intoksikasjon hvis resultatet brukes som en rettesnor og sees i sammenheng med det $\varnothing$ vrige kliniske bildet. 
Intoksikasjon eller akutt forgiftning er et betydelig helseproblem og forårsaker mange sykehusinnleggelser. WHO beskriver intoksikasjon som en forbigående tilstand som resulterer i forstyrrelser i en persons bevissthetsnivå, vurderingsevne, kognisjon, persepsjon, atferd og/eller andre funksjoner og responser (1).

\section{INTOKSIKASJON}

I Norge er 96 prosent av intoksikasjonstilfellene selvpåført (2). I Oslo er forekomsten av sykehusbehandlet intoksikasjon cirka 150 per 100000 personer (3). Intoksikasjon er den vanligste årsaken til nedsatt bevissthet hos pasienter som innlegges på sykehus, og denne gruppen er økende $(2,4)$.

Pasienter med intoksikasjon er en ung pasientgruppe. Medianalderen ved innleggelse for pasienter med selvpåført intoksikasjon i Oslo er 31 år (3). Gjennomsnittsalderen for intoksikasjonspasienter inkludert i undersøkelsen var 32 år.

\section{Hensikt}

Artikkelen tar utgangspunkt i en studie som ble gjennomført som et kvalitetsforbedringsprosjekt på egen avdeling, en medisinsk intensivavdeling på et universitetssykehus i Norge. Hensikten var å undersøke om GCS er et egnet klinisk verktøy til å kartlegge graden av nedsatt bevissthet hos pasienter med intoksikasjon.

Artikkelen bygger på en undersøkelse som ble gjennomført på en intensivavdeling hvor mange typer intoksikasjonspasienter blir behandlet. Ved ankomst dokumenteres pasientens bevissthetsnivå ved hjelp av den såkalte Glasgow Coma Scale (GCS). 
Glasgow Coma Scale (GCS) er et hjelpemiddel som brukes for å overvåke pasientens bevissthetsnivå og å observere og dokumentere eventuelle forandringer i bevissthetsnivået over tid. Ved bruk av GCS skal helsepersonell observere, vurdere og skåre pasientens respons på en skala fra 1 til 4 for øyeåpning, 1 til 5 for verbal respons og 1 til 6 for motorisk respons.

Summen av enkeltskårene gir en totalskår (fra 0-15) som beskriver pasientens bevissthetsnivå. Det er vanlig å angi både enkelt- og totalskår, for eksempel slik: «4 (øyeåpning), 3 (verbal respons), 5 (motorisk respons), GCS $=12 »$.

Kilde: www.glasgowcomascale.org

Både på verdensbasis og i Norge er GCS det mest brukte verktøyet for å vurdere bevissthet hos pasienter både pre- og intrahospitalt (5). Vurderinger av bevissthetsnivå bør utføres tidlig i forløpet fordi tilstanden til intoksikasjonspasienten raskt kan forverres.

Skåring av pasientens bevissthetsnivå kan si noe om hvor pasienten er i sykdomsforløpet, og hvilke tiltak som bør iverksettes. Dette gjør GCS til et sentralt verktøy for sykepleiere som tar imot og behandler pasienter med intoksikasjon.

\section{Erfaringer med GCS}

Glasgow Coma Scale (GCS) ble utviklet i 1974 som et klinisk verktøy for å fastslå, beskrive og måle grad av bevissthet hos postoperative pasienter på en systematisk måte (6). GCS brukes for å overvåke pasientens bevissthetsnivå og observere og dokumentere eventuelle forandringer $\mathrm{i}$ bevissthetsnivået over tid. Skalaen brukes videre som grunnlag i vurderingen av graden av intoksikasjon, antatt rekonvalesenstid og som indikasjon på behov for intubasjon (7). 
Ved bruk av GCS skal helsepersonell observere, vurdere og skåre pasientens respons på en skala fra 1 til 4 for øyeåpning, 1 til 5 for verbal respons og 1 til 6 for motorisk respons. Summen av enkeltskårene gir en totalskår (fra 0-15) som beskriver pasientens bevissthetsnivå.

Det er vanlig å angi både enkelt- og totalskår, for eksempel slik: «4 (øyeåpning), 3 (verbal respons), 5 (motorisk respons), GCS $=12 »(8)$. Ofte intuberes pasienten rett etter ankomst på avdelingen, mens noen ankommer og puster selv. Pasientene kan ha en varierende grad av bevissthet.

Klikk deg gjennom billedgalleriet under for en gjennomgang av skåringsprosessen i GCS:

\section{Uforutsigbart forløp}

Intoksikasjonspasienter er en vanskelig pasientgruppe å behandle av flere årsaker. De krever årvåkenhet fra sykepleieren og et høyt nivå på personalets kliniske vurderingsevne. I tillegg er de involverte behandlerne opptatt av pasientens GCS prehospitalt og i akuttmottak, for å få et bilde av utviklingen av bevissthetsnivået.

Et av kjennetegnene på denne pasientgruppen er et raskt utviklende og uforutsigbart forløp, spesielt hos de pasientene hvor intoksikasjonssubstansen er ukjent. Utfallet av forløpet avhenger av inntatt substans og hvor lang tid det er mellom inntak av stoffet og ankomst på en intensivavdeling (9).

\section{Parallell skåring}


Til tross for omfattende bruk av GCS som

vurderingsmetode eksisterer det ikke en gullstandard

for hvordan en GCS-skåring skal gjennomføres (10).

Etter flere års erfaring med pasienter med forgiftning

bygget det seg opp en nysgjerrighet hos

artikkelforfatteren om GCS var et egnet redskap til

bruk på intoksikasjonspasienter innlagt på intensiv.

\section{三 «Det eksisterer ikke en gullstandard for hvordan en GCS-skåring skal gjennomføres.»}

Derfor ble det gjennomført et

kvalitetsforbedringsprosjekt der alle

intoksikasjonspasientene som ble innlagt på en

intensivavdeling, ble skåret for GCS parallelt, det vil si

at to sykepleiere skåret samme pasient på tilnærmet

samme tidspunkt uten å se hverandres skåringer.

\section{Undersøkelsen}

I undersøkelsen ble 42 pasienter inkludert, og det ble utført 84 GCS-skåringer. Av pasientene var 26 prosent kvinner og 74 prosent menn. Gjennomsnittsalderen for gruppen var 32 år. Femtifem prosent av pasientene hadde en blandingsforgiftning. Den hyppigst brukte substansen som hadde forårsaket en forgiftning, var gammahydroksysmørsyre (GHB).

Sykepleierne som utførte skåringene, hadde et aldersspenn fra 28 til 62 år, med varierende lengde på erfaringen fra en intensivavdeling. Det ble brukt Cohens kappa for å undersøke den såkalte interraterreliabiliteten (IRR), altså graden av samsvar mellom sykepleiernes målinger (11). Kappa-resultatene (ofte forkortet til K) spenner fra 0 til 1 . Figur 1 nedenfor viser kappa-verdiene for sykepleiernes skåringer i denne undersøkelsen. 
Cohens kappa (utviklet av statistikeren Jacob Cohen) er et mål på faktisk overensstemmelse mot tilfeldig overensstemmelse. Verdien viser i hvor stor grad det er samsvar mellom to skåreres vurdering av et fenomen - for eksempel to sensorers karaktersetting av den samme bunken med studentbesvarelser.

Skalaen går fra 0 til 1. En kappa-verdi på 0 indikerer at samsvaret ikke er større enn det ville vært om skåringen var vilkårlig, mens en kappa-verdi på 1 viser at samsvaret mellom skårerne er perfekt. Verdien kan også være negativ; da er samsvaret dårligere enn det man kunne forvente hvis skåringen hadde vært helt tilfeldig.

Kilde: Fleiss JL, Cohen J. The equivalence of weighted kappa and the intraclass correlation coefficient as measures of reliability. Educational and Psychological Measurement. 1973;33(3):613-9.

Om verktøyet er hensiktsmessig å bruke til tross for disse resultatene, er et spørsmål det er naturlig å stille seg. Den videre fremstillingen vil belyse funnene i undersøkelsen, tidligere forskning på området og om GCS er et egnet redskap til bruk på pasienter med forgiftninger.

\section{Metode}

Studien som ble gjennomført, er en beskrivende observasjonsstudie der graden av samsvar mellom to sykepleieres GCS-skåringer ble kartlagt gjennom et an onymisert studieskjema (se under). Hver pasient ble skåret av to sykepleiere så raskt som mulig etter at pasientene ankom intensivavdelingen.

Sykepleierne kunne ikke se hverandres skåringer. Hver sykepleier skåret pasienten med så kort tidsintervall som mulig. På skjemaet ble det også angitt mistenkt substans som forårsaket forgiftningen, pasientens alder og kjønn, GCS-skår i akuttmottaket og om pasienten hadde frie luftveier ved ankomst. 
Studien ble gjennomført i en tidsperiode på sju måneder. Utvalget besto av 42 voksne pasienter, som ikke var intuberte, og som hadde intoksikasjon av alkohol, medikamenter og/eller narkotiske substanser.

Primær innleggelsesårsak var selvpåført intoksikasjon.

Pasienter med kognitiv svikt forårsaket av andre forhold som demens, medfødt eller traumatisk hodeskade eller cerebralt insult (hjerneslag) ble ekskludert. Dataene ble analysert med kappa for å undersøke interrater-reliabiliteten mellom sykepleiernes skåringer (11). Kappa (K) er den statistiske analysen som ofte blir foretrukket i reliabilitetsstudier $(12,13)$.

\section{INTERRATER-RELIABILITET}

Reliabilitet er av interesse når samme fenomen måles av ulike personer. Grad av samsvar omtales som interrater-reliabilitet.

Kilde: Store norske leksikon

\section{Resultater}

Studien viste lavt til moderat samsvar mellom sykepleiernes skåringer (se figur 1). Det vil si at det er relativt stor feilmargin på skåringene.

Figur 1. Kappa-verdier for skåring av intoksikasjonspasienter på øyeåpning, verbal respons og motorikk

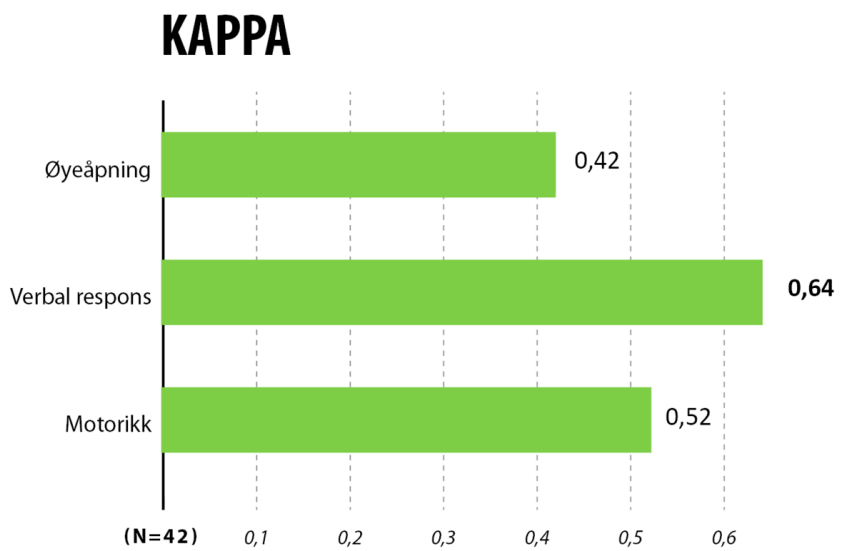


Tabell 1. Hvordan vi kan lese kappa-verdier. $\emptyset$ kende positiv tallverdi betyr $\varnothing$ kende grad av samsvar mellom skårerne

\begin{tabular}{ll}
\hline Verdi av $\mathrm{K}$ & Styrken av samsvar \\
\hline$<0$ & $\begin{array}{l}\text { indikerer ingen enighet eller enighet som er } \\
\text { dårligere enn den man får ved helt tiffeldig skåring } \\
\text { ingen til ubetydelig enighet }\end{array}$ \\
$0,01-0,20$ & lav grad av enighet \\
$0,21-0,40$ & moderat grad av enighet \\
$0,41-0,60$ & betraktelig grad av enighet \\
$0,61-0,80$ & nesten perfekt enighet \\
$0,81-1,00$ & \\
\hline
\end{tabular}

\section{Diskusjon}

GCS har vært gjenstand for forskning i akuttmottak og prehospitalt. Flere studier har satt spørsmålstegn ved anvendbarheten av GCS ved intensivavdelinger $(8,14$, 15). Det er ikke funnet studier som undersøker bruken av GCS blant intoksikasjonspasienter på intensivavdeling, men én studie med intoksikasjonspasienter fra akuttmottak viste en tilnærmet perfekt enighet mellom skårerne (16).

Det er flere forklaringer på at samsvaret mellom skårerne ikke var høyere på den aktuelle intensivavdelingen. For det første er det spesielle utfordringer knyttet til skåring av bevissthetsnivå hos intoksikasjonspasienter. For det andre kan faktorer knyttet til personalets erfaring og opplæring i å bruke verktøyet være avgjørende.

I undersøkelsen ble pasienter med intoksikasjon forårsaket av ulike substanser og varierende grad av bevissthet inkludert. Det advares mot å sette for mye lit til GCS på intoksikasjonspasienter fordi alkohol og narkotiske substanser påvirker bevissthetsnivået til pasienten (17). 
Lav GCS kan ta oppmerksomheten bort fra symptomer på hypoksi, sepsis og septisk sjokk fordi man antar at GCS-en er lav på grunn av intoksikasjonen (17). Sedasjon og smertestillende påvirker pasientens bevissthetsnivå og vanskeliggjør bruken av GCS som verktøy (8).

Pasientene med intoksikasjon kan videre være utfordrende å samarbeide med, spesielt når de er våkne og ruset, fordi ruspåvirkningen kan skape uforutsigbarhet og utagering. For eksempel kan intoksikasjonspasienter oppleves truende og ubehagelige for sykepleieren. Det kan komplisere bruken av GCS som verktøy, fordi GCS krever at pasienten blir smertestimulert og dermed våkner opp fra rusen.

\section{三 «Intoksikasjonspasienter kan oppleves truende og ubehagelige for sykepleieren. Det kan komplisere bruken av GCS.»}

Det er mulig at noe av det lave samsvaret på parallelle målinger med GCS kan forklares med at sykepleierne unnlater å gjennomføre en korrekt GCS-måling. Formålet med å bruke GCS som klinisk verktøy er å forebygge forverring av en pasients tilstand gjennom å dokumentere og observere graden av nedsatt bevissthet. GCS-skåringsresultat kan gi behandler verdifull informasjon som kan identifisere pasienter som står i fare for å utvikle komplikasjoner (18).

Typen intoksikasjonssubstans er en relevant variabel fordi de forskjellig russubstansene gir ulikt rusforløp. Den vanligste substansen i vår undersøkelse er GHB. GHB kjennetegnes ved et fluktuerende rusforløp, med brå oppvåkninger og en plutselig nærmest komatøs dyp søvn med korte og uforutsigbare tidsintervall (19). Det kan ha gitt utslag på resultatene, fordi en pasient kan ha hatt dyp søvn det ene øyeblikket, og bare sekunder senere vært våken og agitert. Derfor kan samme pasient få to svært ulike GCS-skåringer. 


\section{Opplæring}

Helsepersonellets utdannelse, erfaring og type profesjon kan påvirke anvendbarheten i negativ og positiv retning (20). I undersøkelsen ble skåringene utført av sykepleiere med og uten spesialutdanning. På avdelinger hvor det ikke jobbes med traumatiske hodeskader, er personalet muligens mer oppmerksomme på andre vitale tegn som kan forutsi forverring av sykdom, fordi de ikke er trenet i arbeid med hodeskadepasienter.

Det eksisterer ingen spesifikk strukturert opplæring i bruk av GCS på avdelingen. Avdelingen der prosjektet ble gjennomført, var en medisinsk intensivavdeling, uten pasienter med traumatiske hodeskader.

Studier har pekt på at bruk av GCS er komplisert utenfor en nevrokirurgisk/medisinsk setting fordi personalet ikke har erfaring med verktøyet (17). En sykepleier på en intensivavdeling er drillet i ABCprinsippene (airways, breathing, circulation). Sykepleierens kontinuerlige observasjoner kan medføre at han eller hun opplever allerede å ha god oversikt over pasientens bevissthetsnivå, og at vedkommende derfor vurderer GCS som overflødig.

Likevel er GCS viktig å bruke for sin prognostiske verdi og fordi det gir verdifull informasjon som kan identifisere pasienter med risiko for å utvikle komplikasjoner (18).

Personalet på avdelingen der vårt prosjekt ble gjennomført, har varierende erfaring med og trening $\mathrm{i}$ bruk av GCS. I tillegg er det utstrakt bruk av vikarer på avdelingen. Disse faktorene kan bidra til et lavere samsvar i GCS-målingene fordi bruken av skåringsverktøyet kan være inkonsekvent. Før de bruker skåringsverktøy, er det viktig at personalet har riktig opplæring (10). En forutsetning for at GCS skal gi korrekt informasjon om pasientens tilstand, er at helsepersonell benytter den samme metoden for å skåre pasientens bevissthetsnivå. 


\section{Feilkilder}

Når det gjelder selve den praktiske utførelsen av skåringen, kan GCS ha flere potensielle feilkilder som kan påvirke skåringsresultatet. Under skåringskomponentene øyeåpning og motorisk respons kreves det at pasienten blir smertestimulert for å oppnå reaksjon. Det var disse to komponentene som hadde lavest samsvar i vår studie. Flere studier viser at smertestimuleringen utføres forskjellig, noe som er en mulig forklaring på hvorfor sykepleiere skårer ulikt $(17,20)$.

En annen feilkilde kan være personalets tolkning av den verbale komponenten i GCS. Sykepleiernes tolkning av hva som oppfattes som henholdsvis orientert, forvirret og uforståelig tale (se skåringsskjema gjengitt som vedlegg 1), kan være subjektiv (20). Det var likevel skåringen av verbal respons som ga høyest samsvar i undersøkelsen.

I mangel av standardisert bruk av GCS på intensivavdelingen kan ulik og inkonsekvent utførelse av smertestimuli og tolkning av verbal respons bidra til lavt samsvar mellom skåringer.

\section{Brukes forskjellig}

En konsekvens av undersøkelsen kan være økt oppmerksomhet rundt opplæring i bruk av GCS som klinisk verktøy for å kvalitetssikre bruken. Dette er et poeng som repeteres mye i forskningslitteraturen (10). Oppsummert kan personalets erfaring, holdning og manglende opplæring i bruk at GCS bidra til det lave samsvaret mellom skåringene.

\section{三 «Det savnes retningslinjer og en standardisert bruk av GCS. Flere sykepleiere etterlyste dette $\mathrm{i}$ forbindelse med datainnsamlingen.»}


GCS fremstår som et enkelt verktøy å bruke, men det savnes retningslinjer og en standardisert bruk av GCS. Flere sykepleiere etterlyste dette i forbindelse med datainnsamlingen. De var usikre på hvordan en skåring skulle gjennomføres korrekt.

GCS kan være et komplisert verktøy, og forskningen finner alt fra sterk enighet til sterk uenighet når ulike faggrupper skårer samme pasient (8). Dette kan tolkes som at GCS er en skala med mange kompliserende elementer (21).

I tillegg viser tidligere studier at verktøyet brukes forskjellig av ulike profesjonsutøvere, uavhengig av utdannelsesnivå. Tidspunktet for skåringen tenderer til å være inkonsekvent, og det mangler en standardisert manual for bruk på avdelingene (8).

\section{Konsekvenser for praksis}

Resultatene i undersøkelsen ga grunnlag for å sette spørsmålstegn ved om GCS er et egnet verktøy for å måle bevissthetsnivå hos intoksikasjonspasienter. Undersøkelsen fant at det var en lav grad av samsvar i GCS-skåringene av intoksikasjonspasientene innlagt på en intensivavdeling. Sykepleierne skåret altså ikke alltid konsistente målinger av GCS på samme pasient.

\section{三 «Det var for lavt samsvar mellom de parallelle skåringene til at GCS-verdiene kan tillegges stor klinisk betydning.»}

Undersøkelsen viser videre at GCS har flere gode

kvaliteter som klinisk verktøy for pasienter med

intoksikasjon, men at opplæring, trening og

kontinuerlig bruk i sykepleiergruppen er en

forutsetning for pålitelige skåringer. 
Det var for lavt samsvar mellom de parallelle skåringene til at GCS-verdiene kan tillegges stor klinisk betydning. Det trengs mer forskning for å belyse dette videre. Tidligere forskning viser at GCS kan brukes som klinisk rettesnor. Anbefalinger for videre praksis kan være at GCS anses som et egnet verktøy dersom skåringsresultatene sees i relasjon til det øvrige kliniske bildet.

GCS kan oppleves som et komplisert klinisk verktøy. Trening av personalet i bruk av skåringsverktøyet ser ut til å være viktig, og dette er tiltak som nå er iverksatt internt på den avdelingen hvor undersøkelsen ble gjennomført. Bruk av en standardisert manual med praktiske forklaringer er å anbefale. Det kan bidra til å kvalitetssikre bruken av GCS på intoksikasjonspasienter på intensivavdeling.

\section{Referanser}

1. World Health Organization. Management of substance abuse. Acute intoxication [internett]. Genève: WHO; [sitert 04.06.2018]. Tilgjengelig fra: ht tp://www.who.int/substance_abuse/terminology/acute_ intox/en/

2. Ekeberg Ø. Pasienter med selvpåført forgiftning i medisinsk avdeling. Tidsskrift for Den norske legeforening. 2009 april;129(9):882-4.

3. Bakke E, Bogstrand ST, Normann PT, Ekeberg $\varnothing$, Bachs L. Influence of alcohol and other substances of abuse at the time of injury among patients in a Norwegian emergency department. BMC Emerg Med. 2016;16(1):20.

4. Zuercher M, Ummenhofer W, Baltussen A, Walder B. The use of Glasgow Coma Scale in injury assessment: a critical review. Brain Injury. 2009;23(5):371-84.2.

5. Vale A, Bradberry S. Assessment and diagnosis of the poisoned patient. Medicine. 2016;44(2):82-6. 
6. Teasdale G, Jennett B. Assessment of coma and impaired consciousness: a practical scale. The Lancet. 1974;304(7872):81-4.

7. Heyerdahl F, Bjornaas MA, Dahl R, Hovda KE, Nore AK, Ekeberg O, et al. Repetition of acute poisoning in Oslo: 1-year prospective study. The British Journal of Psychiatry. 2009;194(1):73-9.

8. Maignan $\mathrm{M}$, Pommier $\mathrm{P}$, Clot $\mathrm{S}$, Saviuc $\mathrm{P}$, Debaty G, Briot R, et al. Deliberate drug poisoning with slight symptoms on admission: Are there predictive factors for intensive care unit referral? A three-year retrospective study. Basic \& Clinical Pharmacology \& Toxicology. 2014;114(3):281-7.

9. El-Sarnagawy GN, Hafez AS. Comparison of different scores as predictors of mechanical ventilation in drug overdose patients. Hum Exp Toxicol. 2017 juni;36(6):539-46.

10. Heard K, Bebarta VS. Reliability of the Glasgow Coma Scale for the emergency department evaluation of poisoned patients. Human \& Experimental Toxicology. 2004;23(4):197-200.

11. McHugh ML. Interrater reliability: the kappa statistic. Biochemia Medica. 2012;22(3):276-82.

12. Polit DF, Beck CT. Resource manual for nursing research. Wolters Kluwer Health / Lippincott Williams \& Wilkins; 2012.

13. Streiner DL, Norman GR, Cairney J. Health measurement scales: a practical guide to their development and use. USA: Oxford University Press; 2014.

14. Lowry M. Emergency nursing and the Glasgow Coma Scale. Accident and Emergency Nursing. 1998;6(3):143-8. 
15. Green SM. Cheerio, laddie! Bidding farewell to the Glasgow Coma Scale. Annals of Emergency Medicine. 2011;58(5):427-30.

16. Gill MR, Reiley DG, Green SM. Interrater reliability of Glasgow Coma Scale scores in the emergency department. Annals of Emergency Medicine. 2004;43(2):215-23.

17. Braine ME, Cook N. The Glasgow Coma Scale and evidence - Informed Practice: a critical review of where we are and where we need to be. J Clin Nurs. 2017 januar;26(1-2):280-93.

18. Eizadi Mood N, Sabzghabaee A, Yadegarfar G, Yaraghi A, Ramazani Chaleshtori M. Glasgow Coma Scale and its components on admission: Are they valuable prognostic tools in acute mixed drug poisoning? Crit Care Res Pract. 2011 mars.

19. Schep LJ, Knudsen K, Slaughter RJ, Vale JA, Mégarbane B. The clinical toxicology of gammahydroxybutyrate, gamma-butyrolactone and 1,4butanediol. Clinical Toxicology. 2012;50(6):458-70.

20. Reith FC, Van den Brande R, Synnot A, Gruen $\mathrm{R}$, Maas AI. The reliability of the Glasgow Coma Scale: a systematic review. Intensive Care Medicine. 2016;42(1):3-15.

21. Laureys S, Bodart O, Gosseries O. The Glasgow Coma Scale: time for critical reappraisal? The Lancet Neurology. 2014;13(8):755-7. 